This is a pre-copy edited, author-produced PDF of an article accepted for publication in World Development following peer review. The version of record [Binelli, Chiara, Matthew Loveless, and Stephen Whitefield. 2015. "What Is Social Inequality and Why Does it Matter? Evidence from Central and Eastern Europe" World Development 70: 239-248] is available online at: 10.1016/j.worlddev.2015.02.007.

Rights / License: The terms and conditions for the reuse of this version of the manuscript are specified in the publishing policy. For all terms of use and more information see the publisher's website. 


\title{
What Is Social Inequality and Why Does it Matter? Evidence from Central and Eastern Europe
}

\begin{abstract}
As distinct from income or wealth inequality, 'social inequality' is currently poorly understood and, at best, unevenly measured. We conceptualize social inequality as the relative position of individuals along a number of dimensions that measure achieved outcomes and, innovatively, expectations about future outcomes. Using data from 12 Central and Eastern European countries, we find that cross-national patterns of social inequality differ significantly from patterns derived from income inequality measures. Moreover, our measure of social inequality is much better correlated than income inequality with other country differences such as higher levels of economic performance and human development, and stronger political institutions.
\end{abstract}

Key words: Social and Income Inequality; Capabilities; Measurement; Central and Eastern Europe; Human Development; Political Institutions. 


\section{INTRODUCTION}

A crucial question in the study of inequality is "inequality of what" (Sen 1992) or, in other words, which inequality matters? A substantial body of work has converged on the notion that measuring inequality in several dimensions better informs our understanding of the influence of inequality on both individuals and societies. Inequalities in different dimensions tend to move together and reinforce each other. In the large literature on multidimensional inequality a commonly used label for such inequalities is 'social inequality'. While the term is sometimes used to refer to multiple disparities in material wealth in society, little attention has been given to its character and specificities (Milanovic 2005; Bollen and Jackman 1985). That is, this term is used mostly as a catch-all concept rather than as a distinct and coherent concept. ${ }^{1}$

Social inequality remains a vague concept compared with work on inequality in individual dimensions such as in income (Milanovic 1998; Atkinson 1999), wealth (Cagetti and De Nardi 2008), labour market segmentation, gender and ethnicity (Schrover et al. 2007), welfare status (Layte and Whelan 2003), skills and training (Devroye and Freeman 2002), health (Marmot and Wilkinson 1999), and housing (Morris and Winn 1990), to name but a few. Given this, our aim here is to develop a framework to better conceptualize and measure social inequality. In doing so, we face two primary constraints, one theoretical and one methodological. The former constraint is the choice of dimensions to measure social inequality while the latter constraint is aggregating these necessary dimensions without introducing intractable complexity.

We address the theoretical question of the choice of dimensions by conceptualizing social inequality using Amartya Sen's capability approach in which individuals' wellbeing depends on their "effective freedom to achieve" their life goals and full potential $(1992,1999)$. We argue

\footnotetext{
${ }^{1}$ As an example, the entry for 'social inequality' in the Social Science Encyclopaedia (Kuper and Kuper 2004) simply says, 'see inequality'.
} 
that reaching this full potential depends both on having achieved fundamental outcomes such as sufficient income, education, and health as the recognized minimum number of dimensions to measure wellbeing in the Human Development Index, as well as on being able to achieve - and crucially to have expectations of access to the means of achieving - these outcomes in the future. As a consequence, a measure of inequality in the "effective freedom to achieve" will have to take into account disparities both in actual income, education and health, and in their future expected equivalents. Therefore, we conceptualize social inequality as a measure of disparities along a set of minimally required dimensions in actually achieved and expected future outcomes.

In response to the methodological constraint, we propose to aggregate the dimensions into one single index by computing a simple average of inequality measures across the chosen dimensions. We have chosen to aggregate the dimensions into one index rather than presenting a dashboard of individual indicators in order to produce one single index of multi-dimensional inequality, which we will be able both to decompose and to directly correlate with relevant aggregate indicators of political and socio-economic development.

The findings provide several potential, if ambitious, contributions to the thinking about inequality. We propose a framework that allows us to measure 'social inequality' as a single index that captures disparities in both actual achievements and the means to achieve outcomes in the future. The main results show that social inequality defined in this way delivers a better conceptualization than alternatives, particularly measures of income inequality, of the disparities that matter to individuals and their societies. Our social inequality index correlates strongly with cross-national variation in economic and political conditions as well as in human development, while income inequality fails to correlate with any relevant macro aggregate. 


\section{CONSTRUCTING A MULTI-DIMENSIONAL INEQUALITY INDEX}

\subsection{CHOICE OF DIMENSIONS}

Despite the lack of a framework to conceptualize and measure social inequality, there is a consensus that social inequality is an intrinsically multi-dimensional concept, which captures disparities along a number of dimensions that matter for the lives of individuals and the societies where they live. Theoretically, the multi-dimensional measurement of inequality is motivated by Amartya Sen's "capabilities/functionings" approach, which is based on the core concept that wellbeing depends on individuals' "effective freedom to achieve" their life goals and full potential (Sen 1985; 1992; 1999). Empirically, a number of important contributions (e.g. Anand et al. 2009; Alkire 2011), as well as an extensive empirical literature on the economics of happiness (e.g. Oswald 1997; Carbonell and Frijters 2004), have established that a prerequisite for the fulfilment of individuals' subjective wellbeing is achieving outcomes in several dimensions. Simply, wellbeing is intrinsically multi-dimensional and therefore inequality should as well be consistently measured along a number of dimensions.

Our innovation to the multi-dimensional thinking and measuring of inequality is arguing that individuals' wellbeing and effective freedom to achieve depend not only on what a person has actually achieved, but also, and as importantly, on what a person expects to be able to achieve in the future. Actual and future achievements are related as future achievements depend on what has been already achieved as well as on how actual achievements will allow achieving outcomes in the future. That is, the capabilities approach rests on two related notions. One, having choices or the ability to choose among alternative life trajectories - more than mere material wealth - is the indicator of individual freedom; and two, individuals' future expectations - what individuals expect from their future - have significant behavioral consequences now.

In particular, considering how expectations might relate to important potential outcomes in the future, we see the power of expectations as a means to relieve or minimize the impact of 
(future) uncertainty. Being able to rely on or dismiss future alternatives allows individuals to better construct plans and thus choices about future activities. Even in the probabilistic sense, the mere (un)likelihood of future opportunities changes individuals' choices in the present.

Therefore, we argue that a measure of inequality in the effective freedom to achieve should measure disparities in people's abilities to achieve their desired - even if only potential - goals taking into account individuals' present situation and expectations about their future. Consistently, we define social inequality as a capability-based index of inequality that measures disparities both in actual and in potential future outcomes. We further propose to do so along the minimum number of dimensions that have been recognized as fundamental to measure wellbeing, namely, individuals' income, health, and education as included in the Human Development Index (HDI). ${ }^{2}$

While the importance of individuals' levels of income, education and health is self-evident, the challenge is how to measure potential future outcomes along these dimensions. The ideal type of data to elicit information on future outcomes are quantitative expectations data, which collect information on future expected outcomes together with their associated expected probabilities of realization (Manski 2004). For a given outcome of interest, respondents are asked to provide the expected minimum and maximum value that the outcome can take together with the expected probabilities of different quantiles of its distribution, which allows constructing the entire subjective distribution of future realizations in different scenarios to fully capture the role of uncertainty that individuals face when forming expectations.

\footnotetext{
${ }^{2}$ By defining social inequality as a capability-based index of disparities in actual and in potential future outcomes along a minimum number of dimensions, our index of social inequality is conceptually and methodologically different from measures of social cohesion, such as the one developed in Dickes and Valentova (2013).
} 
Unfortunately, to the best of our knowledge, there is no publically available dataset that contains individual-level information on future expected income, education and health. However, we argue that what we can expect of our future outcomes depends on what we expect or perceive to have access to, and that a crucial role is played by perceived access to health care and education that are essential to all future outcomes that an individual can expect to achieve. While there is evidence that individuals' perceptions matter for capabilities and empowerment (e.g. Trommlerová et al. 2015; Welzel 2014), we emphasize the crucial role of perceptions of access to basic services. In particular, the perceived level of access to health care and education are manifestly instrumental and a fundamental prerequisite to the effective achievement of potential outcomes in the future, among which the desired (future) levels of health, education and income. Access to education, for example, is often perceived to be low in a country where education policies tend to favour the elite by 'tilting' public spending towards higher education, which particularly in developing countries (Lloyd and Kosack 2014). Therefore, while we do not equate a perceived gap in access to services to a gap in future expected outcomes, we argue that perceived access is instrumental to the achievement of future expected outcomes since individuals' perceptions of their access to services is one of the factors that drives their current behaviour and therefore the outcomes that they expect to achieve in the future.

Thus, we define social inequality as an index that captures disparities in actual and in potential future outcomes along three core dimensions (income, education, and health): the current level of income, health status and level of education account for actual outcomes, and the perceived access to health care and to education account for future expected outcomes. The importance of perceived access to services is paramount since it reflects the access that individuals have to fundamental services and public goods: inequality in any given dimension is much more problematic in a society that is characterized by a skewed distribution of access to health care and education than in a society where access to services is more widely available. 


\subsection{AGGREGATION METHOD}

Having identified the dimensions to include in the index, an important question is how to aggregate the data on the different dimensions into one single index. There is an extensive literature on the multi-dimensional measurement of inequality. At one end, there are authors who draw conclusions on the overall evolution of inequality by comparing changes in inequality in separate dimensions (e.g. Slottje, Scully, Hirschberg and Hayes 1991; Easterlin 2000; Hobijn and Franses 2001; Neumayer 2003). A disadvantage of this approach is that it makes it difficult to formulate an overall conclusion on the extent of inequality if inequality in one dimension evolves differently from inequality in another dimension. At the other end, there are approaches that first construct a composite multi-dimensional index and then measure the inequality in that index (e.g. Becker et al. 2005; Fischer 2003; McGillivray and Pilarisetti 2004). The disadvantage of this approach is that it reduces the multi-dimensional nature of the problem to one dimension.

A middle approach lies in between these two extremes by using recently developed measures of multi-dimensional inequality. This middle approach has the advantage of avoiding the reduction of a multi-dimensional problem to a one-dimensional one while yet producing an overall index of inequality. Two sophisticated versions of this approach are Decancq et al. (2009) and Decancq and Lugo (2012). Two multi-dimensional indexes that make use of a simplified version of this middle approach are the Human Opportunity Index (HOI), which accounts for disparities in the distribution of access to basic services for children (Paes de Barros et al. 2009) ${ }^{3}$, and the inequality-adjusted Human Development Index (IHDI), which measures wellbeing accounting for the distribution of human development across individuals (Foster et al. 2005).

\footnotetext{
${ }^{3}$ The HOI measures children's access to basic services adjusted for differences associated with initial circumstances such as gender and race; as such it is a development index that controls for inequality of opportunity.
} 
Both the HOI and the IHDI require simple computations and assume that each dimension included in the index weights equally. Following the HOI and IHDI, we propose a multidimensional index of inequality that is easy to compute and retains the assumption of equal weights.

\subsection{COMPUTATION}

Let us assume that there are $M$ relevant variables along which to measure inequality and that these variables can be measured in an interpersonal comparable way. Let $x_{m}^{i j}$ denote the value of individual $i$ in country $j$ for variable $m$ and let the vector $x^{i j}=\left(x_{1}^{i j}, \ldots, x_{M}^{i j}\right)$ summarize the values across all $M$ variables for individual $i$ in country $j$. Let $X^{j}$ define the matrix of all values across all $M$ variables for all individuals in country $j$. The overall index of inequality for a given country $j, I^{j}\left(X^{j}\right)$, which can be rewritten for simplicity as $I^{j}(X)$, can be defined as a function of the $M$ inequality indexes $I_{m}^{j}\left(x_{m}^{j}\right), m=1, . ., M$, computed by aggregating the values of each of the $M$ variables for all $N$ individuals in a given country $j$.

The problem to define a multi-dimensional inequality index in country $j$ can be described as the search for the index $I^{j}($.$) , which aggregates inequality in each of the value vectors$ $x_{1}^{j}, \ldots, x_{M}^{j}$ on the real line so that a natural ranking can be made:

$$
I^{j}(x)=\left[w_{1}^{j} I_{1}^{j}\left(x_{1}^{j}\right)^{\beta}+\ldots+w_{M}^{j} I_{M}^{j}\left(x_{M}^{j}\right)^{\beta}\right]^{1 / \beta}
$$

where $\beta$ is strictly different from zero and $w_{m}>0$ for each $m=1, \ldots, M$.

Therefore, the index $I(x)$ is defined as a simple weighted average of order $\beta$ of $I_{m}\left(x_{m}\right)$ with weights $w_{m}^{j}$, which are allowed to vary by country. ${ }^{4}$

\footnotetext{
${ }^{4}$ As noted by Decancq and Lugo (2013), Maasoumi (1986) provides an information-theoretic justification of this class of indexes. In particular, using a generalized criterion from information
} 
Given a chosen set of $M$ variables, three main components characterize the index $I(x)$ : the parameter $\beta$, the $M$ inequality indexes $I_{m}^{j}\left(x_{m}^{j}\right)$, and the weights $w_{m}^{j}$. The parameter $\beta$ is related to the elasticity of substitution, $\sigma$, between pairs of variables. For a given pair of variables $h$ and $g$, $\sigma_{h g}=\left|\frac{1}{1-\beta}\right|$. The smaller the $\beta$, the bigger the substitutability between two variables, that is the more we need to decrease one variable in order to increase another variable by one unit while keeping the level of the index $I(x)$ constant. By specifying the index $I(x)$ in equation (1) we implicitly assume the same degree of substitutability for all pairs of variables. Further, we assume that $\beta=1$, so that equation (1) reduces to the standard weighted arithmetic average.

In order to compute the inequality index $I_{m}^{j}\left(x_{m}^{j}\right)$ by country and variable, we normalize and rescale the data by subtracting the minimum value and by dividing by the difference between the maximum and the minimum value, and we then compute the Theil index of each $\mathrm{m}$ variable. ${ }^{5}$ In particular, by denoting with $x_{i, m}^{j}$ the value of variable $m$ for individual $i$ in country $j$, and by $x_{m}^{j, \text { Min }}, x_{m}^{j, \text { Max }}$ and $\tilde{x}_{i, m}^{j}$, respectively, the minimum value, the maximum value, and the rescaled value of $x_{i, m}^{j}$, the Theil inequality index of each $m$ variable in country $j$, that is $I_{m}^{j}\left(x_{m}^{j}\right)$, is computed in the following way:

$$
\begin{aligned}
& I_{m}^{j}\left(x_{m}^{j}\right)=\frac{1}{N} \sum_{i=1}^{N} \frac{\tilde{x}_{i, m}^{j}}{\overline{\bar{x}}_{m}^{j}} \log \left(\frac{\tilde{x}_{i, m}^{j}}{\overline{\bar{x}}_{m}^{j}}\right) \\
& \tilde{x}_{i, m}^{j}=\frac{\left(x_{i, m}^{j}-x_{m}^{j, \text { Min }}\right)}{\left(x_{m}^{j, \text { Max }}-x_{m}^{j, \text { Min }}\right)}
\end{aligned}
$$

theory, Maasoumi (1986) shows that such indices provide the most appropriate representation of individual welfare when the object of study is the distribution of welfare in a given population. ${ }^{5}$ The Theil index satisfies the four basic desirable properties in an inequality measure (Shorrocks 1980); as such it has been extensively used in several inequality analyses (Galbraith 2012). 
where $N$ is the number of observations on variable $m$ in country $j$, and $\overline{\bar{x}}_{m}^{j}$ is the average value of the rescaled variable $\tilde{x}_{i, m}^{j}$ for variable $m$ in country $j$.

Finally, we aggregate the $M$ inequality indexes into the overall inequality index for country $j$. We do so by computing the weighted arithmetic average of the $I_{m}^{j}\left(x_{m}^{j}\right)$ inequality indexes for country $j$ with the $w_{m}^{j}$ weights specified in equation (1). Following the procedure used to construct the HOI and IHDI indexes, we assume equal weights. ${ }^{6}$

Therefore, the construction of our social inequality index requires two simple computational steps: first, to normalize and rescale the data; second, to compute the Theil for each of the five variables included in the index, and to take a simple average of the five Theil indexes.

\section{DATA}

The cross-country dataset used in this paper was collected in 2007 as part of the EUREQUAL project 'Social Inequality and Why It Matters for the Economic and Democratic Development of Europe and Its Citizens: Post-Communist Central and Eastern Europe in Comparative Perspective'. The data were collected by national surveys via face-to-face interviews on the basis of stratified national random probability samples with each country's data weighted to $\mathrm{N}=1000$.

\footnotetext{
${ }^{6}$ The assumption of equal weights is computationally easy but imposes an arbitrary choice on the relative importance of each variable included in the index. We have also relaxed the assumption of equal weights and used factor analysis to let the data inform our choice of the weights. Factor analysis is one of several different alternatives to estimate the weights from empirical data (see Decancq and Lugo 2013 for a comprehensive review of the literature). When computing the index as a weighted average with weights estimated using factor analysis, the main empirical results remain substantively unchanged.
} 
Appendix A provides additional details on the EUREQUAL project, on the data collection process and on the construction of the sample.

The EUREQUAL surveys provide a unique opportunity to bring to an empirical test our theory of social inequality. First, the countries of post-Soviet Central and Eastern Europe (CEE) including Russia provide a unique examination of the issue of inequality. This region's reorientation away from Soviet Communism towards market economies and political democracy has met with wide ranging levels of success. Instructively, these countries began a process of transformation at nearly the same time but achieved substantial dissimilarity in consolidation of economic and political institutions. Second, and most importantly, the EUREQUAL dataset, unlike any other available multi-country datasets, includes all the variables that we need to operationalize our capability-based index of social inequality.

As discussed in Section 2.1, we have identified individuals' income, health and education and perceived access to health care and education as the five core variables along which to measure disparities. While individuals' level of income, health and education are recorded by most available individual-level datasets, the EUREQUAL dataset also includes a measure of perceived access to health and education by asking individuals to report their perceived access to health care and education compared to "...the average access in the country as a whole."

These two access variables allow us to measure self-reported perceived access to services and thus to empirically substantiate the innovative component of our index that captures the role of disparities in potential future outcomes. Assessing "access" is a means by which individuals see potential needs - in this case, health and education - being met in the future. In other words, perceived access to health and education reduces uncertainty about the future and thus about the decisions that can be taken. For example, if respondents report high levels of perceived access to health or education, this can support potential future ventures. On the other hand, if the 
respondents report low levels of perceived access to either, this may reduce the number of potential future choices. In either case, future uncertainty is reduced.

We combine the two perceived access variables with standard survey questions on (pre-tax) households' income, individuals' health status and education level, which we use to measure the three achieved outcomes. As we already discussed, we have chosen to focus on income, education and health measured in actual and potential outcomes as a minimum number of core dimensions that are fundamental for individuals' wellbeing, in congruence with the substantial body of work that motivated the introduction of the HDI, which measures countries' level of achievement using a measure of income, education, and health (Fukuda-Parr 2003).

Appendix B provides full details on the questions used to elicit information on each of the five variables included in our index, which we compute for a total of 12 countries (Belarus, Bulgaria, Czech Republic, Estonia, Hungary, Latvia, Lithuania, Moldova, Romania, Russia, Slovakia, and Ukraine). Table 1 presents summary statistics by country. Means and standard deviations show that the within country variation of each variable is comparable across-country even if the absolute number of observations varies both among the five variables, particularly for income and perceived access to education, and between the 12 countries in the sample with Russia being the country with the biggest number of observations for each variable.

\section{$<$ Table 1 about here>}

Taken together, the five variables in the index are fundamental to enhance the individual's capability set by allowing for a satisfactory and rewarding life. Taking away any one of someone's income, health, education or preventing their access to health care and education would restrict the opportunities and effective freedom available to an individual, and would increase the level of social inequality in the country where the individual lives. 


\section{MAIN RESULTS}

Having chosen the variables to include, we can proceed to compute our multi-dimensional social inequality index $I(x)$ in equation (1) for each of the 12 countries in the sample. Figure 1 presents the multi-dimensional social inequality index, which from here onwards for brevity we will call MDII index, by country together with the most commonly used macro-economic inequality indicator - the Gini index for income inequality computed using available online data from the United Nations Development Programme (full details in Appendix B).

\section{$<$ Figure 1 about here >}

Being a simple average of Theil inequality indexes, the index is very easy to read: the higher the score, the higher the level of multi-dimensional inequality. Figure 1 makes it clear that crossnational patterns of social and income inequality differ significantly. Russia and Lithuania are the two countries in the sample with the highest levels of income inequality, while they have low to medium levels of social inequality with the value of the MDII for Russia set at the sample average and the MDII for Lithuania below sample average. Reversely, Moldova and Romania are the most socially unequal countries while having a level of income inequality that is around the sample average.

Looking at the social inequality index alone, Slovakia has the lowest level of inequality and Moldova the highest with a difference of nine percentage points between them. For these postCommunist states, the variation in the quality and extent of both democratization and market liberalization match the generally expected contours of these related processes. While it may seem somewhat counter-intuitive to see countries such as Russia, Ukraine, and Bulgaria having similar levels of social inequality, our multi-dimensional index of social inequality accounts for achieved and potential outcomes (in the form of perceived 'access').

The main innovation of our index is arguing that individuals' wellbeing depends not only on what a person has actually achieved, but also, and as importantly, on what a person expects to be 
able to achieve in the future. In order to better test the innovativeness of including future expected outcomes, we have developed the simplest possible multi-dimensional inequality index by measuring disparities along the three basic dimensions that have been recognized as fundamental prerequisites for individuals' wellbeing (income, health and education). By keeping the number of dimensions at a minimum, we trade off in richness and inevitably reduce the extent of variation of the index between countries. The balancing of actual and potential outcomes is one facet of the contribution of our index and in order to further assess the validity of this balance, we investigate the role of the two perceived access variables.

\subsection{THE ROLE OF PERCEIVED ACCESS}

The main innovation of our index with respect to all existing multi-dimensional indexes of inequality is the inclusion of the two perceived access variables, wich captures the theoretical innovation of measuring disparities along potential future outcomes as a fundamental requirement to measure the inequality that matters to individuals' lives and their socities.

In order to assess the importance of the perceived access variables we recompute the index without them. Table 2 reports the results of the baseline MDII, and the MDII computed without the perceived access to health and to education, together with two additional colums that present the inequality ranking by country (in ascending order with "1" indicating the most unequal country in the sample) for each of the two indices.

\section{$<$ Table 2 about here $>$}

As expected, the two indexes are correlated (correlation coefficient 0.62 with a P-Value of 0.03). In addition to this, the comparison between the baseline MDII and the MDII computed without the perceived access variables shows that the exclusion of the access variables does not substantially affect the social inequality ranking in the sample with Moldova remaining the most socially unequal and Slovakia remaining the least socially unequal. However, it does 
significantly affect the overall extent of social inequality: both the average value and the standard deviation of the MDII computed without the access variables are around two percentage points higher than the corresponding values computed for the baseline MDII index, and the difference in social inequality between the most unequal and the least unequal country in the sample increases from nine percentage points when the baseline MDII index is used to 13 percentage points when the index is computed without the access variables.

Therefore, the results show that when the MDII index accounts for disparities in perceived access to health and education both the average value of inequality and the cross-country variation of the MDII in the sample decrease. This shift in the distribution, and in particular the decrease in the sample variance of the MDII, may raise the concern that the subjective questions that we use to elicit perceived access to health and to education induce repondenst to provide anwers that tend to be closer to the population average. We can dimiss this concern for two main reasons. First, while the use of abstract-type of questions could induce such bias in the reported answers, access to health care and education are concrete and measurable objects in society. Therefore, while eliciting information on individuals' perceived level of access to services is subjective, it is not abstract since it refers to the factual experience of accessing basic services.

Second, the wording of the questions itself may alleviate the concern that individuals' responses simply reflct the population average since the population average is given as a benchmark in the question (i.e.: "please compare your household's access to health care with the average access in the country as a whole?"). That is, respondents were asked to consider the (perceived) average access in their country and to position themselves accordingly.

The different amount of inequality measured when disparities in perceived access to health and to education are accounted for underscores the fundamental importance of assessing inequalities in future expected outcomes in order to obtain a robust picture of the extent of social inequality that characterizes a society. Once social ineqality has been correctly measured, it is 
possible to design appropriate policy interventions to tackle this inequality. However, the usefulness of the MDII for policy analysis crucially depends on how informative this index is on the political, economic and social development of a country. Does the MDII capture information on the set of disparities that matter for individuals' lives and does it therefore correlate with the level of political, economic and social development of a country? Also, how does the MDII compare against the most commonly used indicator of income inequality?

\section{INEQUALITY AND CROSS-NATIONAL PERFORMANCE}

In the literature, income inequality has overwhelmingly been the most studied inequality concept and as such the common understanding of inequality is largely couched in narrowly economic terms. However, a number of studies have shown that changes in income inequality do not necessarily move predictably with changes in other dimensions of inequality; or, in other words, that being economically poor or having a low income is not necessarily a good indicator of being disadvantaged (e.g. Narayan et al. 2000; Alkire 2011).

Further, inequality in non-income dimensions has large impacts on development as countries with less human development tend to have greater inequality in more dimensions, or, in other words, more human development is associated with fewer inequalities (UNDP 2010). Likewise, the distribution of income is at best an inconsistent predictor of the distribution of non-income dimensions of individuals' wellbeing. Not surprisingly, therefore, aggregate income inequality, even when coupled with individuals' socio-economic locations, struggles to provide consistent and predictable indications of broader social, economic, and political opportunities in individuals' lives (Wilkinson and Pickett 2009; Bartels 2008; Kaltenhaler et al. 2008; Bollen and Jackman 1985; Goodin and Dryzek 1980).

Given these findings, it is likely that the poor macro-performance of income inequality may be due to income - alone - being unable to capture information on the set of disparities that matter for individuals' lives. We investigate this by correlating the most commonly used 
indicator for income inequality, the Gini index for income inequality, with the Human Development Index as the indicator for the level of human development in a country, and with a set of standard political and economic macro-indicators. In particular, we consider measures of 'Political Stability' and 'Government Effectiveness' ('Governance Matters VIII' project of the World Bank; Kaufmann et al. 2011), and Freedom House Scores, all measured in 2007, as indicators of political performance, and the 2007 GDP per capita, the five year growth of GDP per capita between 2002 and 2007, and the annual total unemployment rate in 2007 as economic indicators. Data sources for each macro-indicator are described in Appendix B.

\section{$<$ Table 3 about here $>$}

Table 3 shows that income inequality fails to move with each economic and political indicator in any meaningful way: the Gini index for income inequality fails to correlate with both GDP per capita $(\mathrm{r}=-0.02, \mathrm{p} \leq 0.91)$ and GDP growth $(\mathrm{r}=-0.08, \mathrm{p} \leq 0.62)$, as well as with the unemployment rate $(\mathrm{r}=-0.39, \mathrm{p} \leq 0.21)$, political stability $(\mathrm{r}=-0.12, \mathrm{p} \leq 0.43)$ and government effectiveness $(\mathrm{r}=0.06$, $\mathrm{p} \leq 0.69$ ). This finding is consistent with the previous literature and is somewhat disconcerting as the Gini index for income inequality is a frequently used and relied upon indicator of not only disparities in income but also as a proxy of other disparities that impact individuals' lives.

In contrast to this assumption, the MDII is constructed to capture much of the non-income inequality that affects individuals. By including not only achieved outcomes (among which income), but also perceived access to health and education, we expect our index to provide a better indicator of the inequality that matters to individuals and their societies, and thus to countries' economic and political progress. We find this here. In contrast to the poor performance of the Gini index for income inequality, the MDII correlates strongly and in the expected direction with both the level and the growth of per capita GDP (both at $\mathrm{p}<0.05$ ), as well as with the level of unemployment rate and with political stability (both at $\mathrm{p}<0.10$ ). 
In addition, and consistently with previous results (e.g. Alkire 2011; UNDP 2010; Wilkinson and Pickett 2009), the Gini index for income inequality is uncorrelated with the Human Development Index, while the MDII strongly is. Further, and confirming the importance of future expectations, we also show that the index computed without the two perceived access variables correlates less strongly with the economic indicators and with the Human Development Index, and fails to correlate with political stability. Taken together, all these correlations suggest that richer countries with less unemployment, better political institutions and higher human development tend to also be countries with lower levels of multi-dimensional social inequality.

Further, to place both the Gini for income inequality and our social inequality index in direct comparison, Table 4 presents the results of a series of OLS regressions where each macro variable is regressed against the MDII and the Gini index.

\section{$<$ Table 4 about here $>$}

The regression results in Table 4 buttress the findings in Table 3. While the Gini for income inequality fails to reach significance with all the macro variables, the baseline MDII index is statistically significantly correlated with the level and the growth of per capita GDP, with political stability (at $\mathrm{p}<0.10$ ), and with the Human Development Index. ${ }^{7}$ In addition, and confirming both the results of the correlations and the importance of future expectations, unreported results (available upon request) show that the index computed without the two perceived access variables has a worse aggregate performance by failing to correlate with political stability. The importance of the access variables underscore the role of future expected outcomes to capture the inequality that matters to individuals and societies. That is, aggregate

\footnotetext{
${ }^{7}$ There is no issue of multi-collinearity as the MDII is not significantly correlated with the level of Gini index of income inequality $(\mathrm{r}=0.29, \mathrm{p} \leq 0.35, N=12)$.
} 
inequality in what individuals perceive to be their future circumstances can have significant behavioural consequences in the present.

All these results taken together provide evidence that inequalities in non-income dimensions as well as in expectations of future outcomes have an important independent explanatory power that cannot be effectively proxied by variation in income alone, and that the addition of these non-income dimensions to our social inequality index results in a better indicator of the inequality that matters to individuals and their societies. In other words, the results show that the crucial source of variation that is allowing our index to better explain cross-country variation in economic, political and human development is provided by disparities in health, education and in the perceived access to health and education. In doing so, these empirical findings bring supportive evidence to our capability-based concept of social inequality that reflects disparities in actual achievements and - crucially - in perceived access to services, which we see as instrumental to future outcomes and thus to a full achievement of the 'freedom to achieve'.

\subsection{DISCUSSION}

The results show that in our sample of CEE countries the MDII better predicts cross-country variation in human development, economic and political outcomes than a standard measure of income inequality. The results also show that accounting for disparities in perceived access to health and education is crucial to meaningfully measure social inequality as a set of disparities that matter for individuals' lives and therefore correlates with the level of political, economic and social development of a country. First, we show that excluding the perceived access variables from the index significantly affects the overall extent of social inequality (Section 4.1), and, second, that the index computed without the access variables correlates less strongly with macroeconomic indicators and with the Human Development Index, and fails to correlate with political stability (Section 5). Therefore, the results imply that CEE countries with better education and health outcomes as well as better perceived access to health care and education 
have, on the whole, higher levels of human development, better economic performance, and stronger democratic political institutions.

Our empirical analysis is limited by the availability of a small sample. However, the dataset is the only available multi-country source of individual-level information on all the variables that we need to operationalize our capability-based index of social inequality, and as such it remains useful to provide informative descriptive evidence that supports the theoretical innovation of this paper.

In addition, studying social inequality in a sample of Central and Eastern European countries provides useful and important insights to the study of inequality. Two-thirds of the countries in our sample, including Estonia and the Czech Republic, have been members of the European Union since 2004 and thus represent near ideal transition cases towards these institutional arrangements while others, such as Russia and Ukraine, have demonstrated more troubled or partial transitions. We see this as an advantage over existing studies. Countries of recent and ongoing transition present crucial cases of inequality because inequality challenges the new 'rules of the game'. That is, rather than merely troubling to established democracies such as Germany, the UK, or the US, inequality poses a more substantive threat to the edifice and continuation of democratic politics and thus regime stability and legitimacy in these lesser-established democracies. Therefore, a multi-dimensional inequality index that goes beyond income inequality contributes to our knowledge about the extent, stability, and quality of democratic outcomes given the wide variation in outcomes found in our sample.

Further, the context of these data provides some preliminary if provocative grounds for generalizability. Expectations could have an important role in sustaining inequality. In particular, for regions that suffer from perpetual high levels of inequality, such as Latin America, an index of social inequality accounting for disparities in actual and, importantly, expected future outcomes, could provide an alternative perspective on the constituent elements of tenacious 
national levels of inequality. Expectations of limited access to basic services such as health and education, particularly in countries where basic services of high quality are predominantly provided by an expensive private sector, could be a main factor fuelling persistent levels of high inequalities. That is, individuals' future expectations provide a potential contribution to the current way of seeing and thus understanding the origin, cross-national variation, and impact of social inequality.

\section{CONCLUSION}

The goal of this paper is to provide a theory and a method to measure social inequality as the inequality in a number of actual and potential future dimensions that matter to individuals' lives and their societies. We propose a capabilities-based index of social inequality that includes disparities in achieved outcomes (income, education and health status) and in individuals' perceived access to health care and education, which is instrumental to effectively achieve outcomes in the future. We provide an empirical application of our index by using data from 12 Central and Eastern European (CEE) countries in 2007. If focusing on CEE countries clearly limits the generalizability of the results, the strong correlations between the social inequality index and a number of important macro-aggregates provide evidence of a strong statistical relationship. The way forward is to collect data that measure achieved and potential future outcomes for a substantial sample of countries.

We do not assert that our index as it is specified here represents a final model. Rather it is the first step towards a theoretical framework where social inequality is characterized as the relative position of individuals along several social, economic and political dimensions, which, crucially, include potential future outcomes. A number of alternative dimensional specifications are clearly available; however, we do assert that our index does contain the essential dimensions. Most importantly, it is the inclusion of both achieved outcomes and variables that measure how these 
achieved outcomes can allow future achievements that constitute our main contribution to the study of multi-dimensional inequality.

We have found that cross-national patterns of social inequality in CEE countries differ significantly from patterns identified when using more common comparative inequality measures such as the Gini index for income inequality. Importantly, these cross-national patterns show that countries which have less social inequality exhibit higher levels of human development, better economic performance and stronger political stability. In contrast, income inequality fails to substantially correlate with any of the relevant and common macro-indicators of economic and political performance.

We do not confront the notion that income inequality matters for individual choices when it is measured at a disaggregated level at which it is directly experienced by individuals in their daily life such as among their neighbors or peers (e.g. Stark and Taylor 1991). On the contrary, our results show that when income inequality is measured at the aggregate level it merely indicates an environment in which broader sets of disparities are activated. Inequalities in different dimensions tend to move together and reinforce each other, thus rising levels of income inequality in a given country often only exacerbate - rather than capture - the more salient disparities as individuals experience them.

Taken together, the empirical results are consistent with the extensive literature on the conceptualization and on the measurement of individual capabilities, which has established that wellbeing is intrinsically multi-dimensional; therefore, inequality should as well be consistently measured along a number of dimensions. Our main innovation is arguing that individuals' wellbeing depend not only on what a person has actually achieved, but also, and as importantly, on what a person expects to be able to achieve in the future. Therefore, a measure of inequality should account for disparities in people's abilities to achieve their desired - even if only potential - goals taking into account individuals' present situation and expectations about their future. 


\section{REFERENCES}

Alkire, Sabina. (2011). "Multidimensional Poverty and its Discontents", OPHI Working Paper No. 46. published in Measure for Measure: How well do we measure development? Proceedings of the 8th AFD/EUDN Conference, pages 53-90, Paris: AFD.

Anand, Paul, Graham Hunter, Ian Carter, Keith Dowding, Francesco Guala, and Martin Van Hees. (2009). "The Development of Capability Indicators", Journal of Human Development and Capabilities, 10(1): 125-152.

Atkinson, Anthony B. (1999). "Income Inequality in the UK", Health Economics, 8(4): 283-288.

Bartels, Larry. (2008). Unequal Democracy: The Political Economy of the New Gilded Age. Princeton: Princeton University Press.

Becker, Gary S., Tomas J. Philipson, and Rodrigo R. Soares. (2005). “The quantity and quality of life and the evolution of world inequality", American Economic Review, 95(1): 277-291.

Bollen, Kenneth A. and Robert W. Jackman. (1985). "Political Democracy and the Size Distribution of Income”, American Sociological Review, 50(4):438-457.

Cagetti, Marco, and Maria Cristina De Nardi. (2008). "Wealth Inequality: Data and Models", Macroeconomic Dynamics, 12(S2): 285-313.

Carbonell A and P. Frijters. (2004). "How Important is Methodology for the Estimates of the Determinants of Happiness", Economic Journal, 114: 641-59.

Decancq, Koen and Maria Ana Lugo. (2012). "Inequality of Wellbeing: A Multidimensional Approach” Economica, 79(316): 721-746.

Decancq, Koen and Maria Ana Lugo. (2013). "Weights in Multi-dimensional Indices of Wellbeing”, Econometric Reviews, 32(1): 7-34. 
Decancq, Koen, Andre' Decoster, and Erik Schokkaert. (2009). "The Evolution of World Inequality in Wellbeing”, World Development, 37(1): 11-25.

Devroye, Dan, and Richard B. Freeman. (2002). "Does inequality in skills explain inequality of earnings across advanced countries?" CEP, London School of Economics and Political Science, London, UK. Available at: https://ideas.repec.org/p/cep/cepdps/dp0552.html

Dickes, Paul, and Marie Valentova. (2013). "Construction, Validation and Application of the Measurement of Social Cohesion in 47 European Countries and Regions", Social Indicators Research, 113(3): 827-846.

Easterlin, Richard A. (2000). "The worldwide standard of living since 1800", Journal of Economic Perspectives, 14(1): 7-26.

Fischer, Stanley. (2003). "Globalization and its Challenges”, American Economic Review, 93(2): $1-30$.

Foster, James E., Luis F. Lopez-Calva, and Miguel Szekely. (2005). "Measuring the Distribution of Human Development: methodology and an application to Mexico", Journal of Human Development and Capabilities, 6(1): 5-25.

Fukuda-Parr, Sakiko. (2003). "The Human Development Paradigm: Operationalizing Sen's Ideas on Capabilities", Feminist Economics, 9 (2-3): 301-317.

Galbraith, James K. (2012). Inequality and Instability. New York: Oxford University Press.

Goodin, Robert E., and John Dryzek. (1980). "Rational Participation: The Politics of Relative Power", British Journal of Political Science, 10(3): 273-92.

Hobijn, Bart, and Phil Hans Franses. (2001). “Are living standards converging?”, Structural Change and Economic Dynamics, 12(2): 171-200. 
Kaltenhaler, Karl, Stephen Ceccoli, and Ronald Gelleny. (2008). “Attitudes toward Eliminating Income Inequality in Europe”, European Union Politics, 9(2):217-241.

Kaufmann, Daniel, Aart Kraay, and Massimo Mastruzzi. (2011). "The Worldwide Governance Indicators: A Summary of Methodology, Data and Analytical Issues", Hague Journal on the Rule of Law, 3(2): 220-246.

Kuper, Adam, and Jessica Kuper. (2004). The Social Science Encyclopaedia. Routledge.

Layte, Richard and Christopher T. Whelan. (2003). "Moving In and Out of Poverty: The Impact of Welfare Regimes on Poverty Dynamics in the EU', European Societies, 5(2): 167-191.

Lloyd, Gruber and Stephen Kosack. (2014). "The Tertiary Tilt: Education and Inequality in the Developing World", World Development, 54: 253-272.

Maasoumi, Esfandiar. (1986). "The measurement and decomposition of multi-dimensional inequality", Econometrica, 54(4): 991-97.

Manski, Charles F. (2004). “Measuring Expectations”, Econometrica, 72(5): 1329-1376.

Marmot, Michael and Richard Wilkinson. (1999). Social Determinants of Health. Oxford: Oxford University Press.

McGillivray, Mark and J. Ram Pillarisetti. (2004). "International inequality in wellbeing", Journal of International Development, 16: 563-574.

Milanovic, Branko. (1998). Income, Inequality and Poverty during the Transition from Planned to Market Economy. The World Bank; Washington D.C.

Milanovic, Branko. (2005). Worlds Apart. Measuring International and Global Inequality. Princeton University Press; Princeton 
Morris, Jenny and Martin Winn. (1990). Housing and Social Inequality. Hilary Shipman Ltd.

Narayan, Deepa, Raj Patel, Kai Schafft, Anne Rademacher, and Sarah Koch-Schulte (eds.). (2000). Voices of the Poor: Can Anyone Hear Us? World Bank: New York, N.Y: Oxford University Press.

Neumayer, Erik. (2003). "Beyond Income: Convergence in Living Standards, Big Time", Structural Change and Economic Dynamics, 14(3): 275-296.

Oswald A J. (1997). "Happiness and Economic Performance”, Economic Journal, 107, 18151831

Paes de Barros, Ricardo, Francisco H. G. Ferreira, Jose' R. Molinas Vega, and Jaime Saavedra Chanduvi (eds.). (2009). Measuring Inequality of Opportunities in Latin America and the Caribbean. The World Bank.

Schrover, Marlou, Joanne Van der Leun, and Chris Quispel. (2007). "Niches, Labour Market Segregation, Ethnicity and Gender", Journal of Ethnic and Migration Studies, 33(4): 529-540.

Sen, Amartya K.. (1985). Commodities and Capabilties. Oxford: Oxford University Press.

Sen, Amartya K.. (1992). Inequality Reexamined. Oxford: Oxford University Press.

Sen, Amartya K.. (1999). Development as Freedom. Oxford: Oxford University Press.

Shorrocks, Anthony F. (1980). "The Class of Additively Decomposable Inequality Measures”, Econometrica, 48(3): 613-625.

Slottje, Daniel J., Gerald Scully, Joseph G. Hirschberg, and Kathy J. Hayes. (1991). Measuring the Quality of Life Across Countries. Westview Press. 
Stark, Oded, and J. Edward Taylor. (1991). "Migration Incentives, Migration Types: The Role of Relative Deprivation”, The Economic Journal, 101(408): 1163-1178.

Trommlerová, Sofia Karina, Stephan Klasen, and Ortrud Leßmann. (2015). "Determinants of Empowerment in a Capability-Based Poverty Approach: Evidence from The Gambia”, World Development, 66: 1-15.

United Nations Development Programme. (2010). Human Development Report 2010.

Welzel, Christian. (2014). "Evolution, Empowerment, and Emancipation: How Societies Climb the Freedom Ladder", World Development, 64: 33-51.

Wilkinson, Richard G. and Kate Pickett. (2009). The Spirit Level: Why More Equal Societies Almost Always Do Better. London: Penguin. 
Table 1: Mean, Standard Deviation (SD), and Number of Observations (N) by Country and Variable

\begin{tabular}{|l|c|c|c|c|c|c|c|c|c|}
\hline & \multicolumn{4}{|c|}{ Income } & \multicolumn{3}{c|}{ Health } & \multicolumn{3}{c|}{ Education } \\
\hline & Mean & SD & N & Mean & SD & N & Mean & SD & N \\
\hline Belarus & 3.232 & 1.759 & 859 & 3.22 & 0.851 & 1000 & 3.173 & 1.385 & 1000 \\
\hline Bulgaria & 3.233 & 1.374 & 870 & 3.389 & 0.969 & 998 & 3.642 & 1.538 & 998 \\
\hline Czech Rep & 3.411 & 1.891 & 783 & 3.374 & 0.928 & 991 & 2.899 & 1.482 & 985 \\
\hline Estonia & 3.253 & 1.459 & 908 & 3.429 & 0.915 & 1057 & 3.054 & 1.547 & 1057 \\
\hline Hungary & 3.131 & 1.785 & 731 & 3.222 & 1.064 & 1027 & 2.682 & 1.104 & 1028 \\
\hline Latvia & 3.161 & 1.657 & 830 & 3.212 & 0.846 & 1001 & 3.334 & 1.456 & 1001 \\
\hline Lithuania & 2.873 & 1.612 & 813 & 3.421 & 0.863 & 1001 & 3.119 & 1.239 & 1001 \\
\hline Moldova & 3.055 & 1.729 & 750 & 2.867 & 0.928 & 1039 & 3.152 & 1.910 & 1039 \\
\hline Romania & 3.139 & 1.755 & 1176 & 3.249 & 0.997 & 1488 & 2.823 & 1.239 & 1492 \\
\hline Russia & 3.058 & 1.729 & 1668 & 3.201 & 0.882 & 2000 & 2.684 & 1.288 & 2000 \\
\hline Slovakia & 3.430 & 1.870 & 758 & 3.669 & 0.872 & 1032 & 2.877 & 1.130 & 1032 \\
\hline Ukraine & 3.481 & 1.403 & 1358 & 3.032 & 0.890 & 1496 & 3.061 & 1.359 & 1500 \\
\hline
\end{tabular}

\begin{tabular}{|l|c|c|c|c|c|c|}
\hline & \multicolumn{3}{|l|}{ Perceived Access to Health } & \multicolumn{3}{c|}{ Perceived Access to Education } \\
\hline & Mean & SD & N & Mean & SD & N \\
\hline Belarus & 3.698 & 0.984 & 950 & 3.664 & 1.060 & 878 \\
\hline Bulgaria & 3.208 & 1.197 & 969 & 3.619 & 1.178 & 754 \\
\hline Czech Rep & 3.847 & 0.789 & 944 & 3.935 & 0.961 & 875 \\
\hline Estonia & 3.847 & 1.223 & 1010 & 4.119 & 1.321 & 815 \\
\hline Hungary & 3.749 & 0.875 & 1009 & 3.828 & 0.856 & 868 \\
\hline Latvia & 3.529 & 1.179 & 974 & 3.634 & 1.199 & 853 \\
\hline Lithuania & 3.569 & 1.280 & 947 & 3.659 & 1.278 & 847 \\
\hline Moldova & 3.305 & 1.187 & 1002 & 3.595 & 1.119 & 918 \\
\hline Romania & 3.347 & 1.367 & 1437 & 3.652 & 1.459 & 1383 \\
\hline Russia & 3.172 & 1.174 & 1892 & 3.216 & 1.193 & 1674 \\
\hline Slovakia & 3.983 & 0.846 & 983 & 4.206 & 1.000 & 974 \\
\hline Ukraine & 2.920 & 1.185 & 1479 & 3.005 & 1.239 & 1334 \\
\hline Source: EUREQUAL Mass Publics Surveys 2007 \\
\hline
\end{tabular}


Table 2: Baseline Social Inequality Index (MDII) and Social Inequality Index Without Perceived Access Variables by Country

\begin{tabular}{|r|c|c|c|c|}
\hline Country & $\begin{array}{c}\text { MDII } \\
\text { Baseline Index }\end{array}$ & $\begin{array}{c}\text { MDII } \\
\text { No Access Variables }\end{array}$ & $\begin{array}{c}\text { Country ranking } \\
\text { based on MDII } \\
\text { Baseline }\end{array}$ & $\begin{array}{c}\text { Country ranking } \\
\text { based on MDII } \\
\text { No Access } \\
\text { Variables }\end{array}$ \\
\hline Belarus & 0.08 & 0.09 & 5 & 5 \\
\hline Bulgaria & 0.09 & 0.10 & 4 & 4 \\
\hline Czech Republic & 0.08 & 0.10 & 5 & 4 \\
\hline Estonia & 0.08 & 0.09 & 5 & 5 \\
\hline Hungary & 0.07 & 0.09 & 6 & 3 \\
\hline Lithuania & 0.10 & 0.12 & 5 & 4 \\
\hline Moldova & 0.08 & 0.10 & 1 & 2 \\
\hline Romania & 0.15 & 0.21 & 2 & 4 \\
\hline Russia & 0.13 & 0.14 & 4 & 6 \\
\hline Slovakia & 0.06 & 0.10 & 4 & 5 \\
\hline Ukraine & 0.09 & 0.08 & & \\
\hline Source: EUREQUAL Mass Publics Surveys 2007 & 0.09 & & 5 \\
\hline
\end{tabular}


Table 3: Correlations between Macro Indicators and Gini Index for Income Inequality, Baseline Social Inequality Index (MDII) and MDII Without Perceived Access Variables

\begin{tabular}{|c|c|c|c|c|c|c|c|}
\hline \multirow{4}{*}{$\begin{array}{c} \\
\text { Political } \\
\text { Performance }\end{array}$} & & \multicolumn{2}{|c|}{$\begin{array}{c}\text { Gini Index } \\
\text { Income Inequality }\end{array}$} & \multicolumn{2}{|c|}{ Baseline MDII } & \multicolumn{2}{|c|}{$\begin{array}{c}\text { MDII No } \\
\text { Access Variables }\end{array}$} \\
\hline & $\begin{array}{l}\text { Political } \\
\text { Stability }\end{array}$ & $\mathrm{r}=-0.25$ & $\begin{array}{l}\mathrm{p} \leq 0.43 \\
(N=12)\end{array}$ & $\mathrm{r}=-0.56$ & $\begin{array}{l}\mathrm{p} \leq 0.06 \\
(N=12)\end{array}$ & $\mathrm{r}=-0.45$ & $\begin{array}{l}\mathrm{p} \leq 0.14 \\
(N=12)\end{array}$ \\
\hline & $\begin{array}{l}\text { Government } \\
\text { Effectiveness }\end{array}$ & $\mathrm{r}=-0.06$ & $\begin{array}{l}\mathrm{p} \leq 0.85 \\
(N=12)\end{array}$ & $\mathrm{r}=-0.48$ & $\begin{array}{l}\mathrm{p} \leq 0.11 \\
(N=12)\end{array}$ & $\mathrm{r}=-0.39$ & $\begin{array}{l}\mathrm{p} \leq 0.20 \\
(N=12)\end{array}$ \\
\hline & $\begin{array}{r}\text { Freedom } \\
\text { House Score }\end{array}$ & $r=0.24$ & $\begin{array}{l}\mathrm{p} \leq 0.46 \\
(N=12)\end{array}$ & $\mathrm{r}=0.21$ & $\begin{array}{l}\mathrm{p} \leq 0.52 \\
(N=12)\end{array}$ & $\mathrm{r}=0.22$ & $\begin{array}{l}\mathrm{p} \leq 0.49 \\
(N=12)\end{array}$ \\
\hline \multirow{3}{*}{$\begin{array}{c}\text { Economic } \\
\text { Performance }\end{array}$} & $\begin{array}{r}\text { GDP per } \\
\text { capita }\end{array}$ & $\mathrm{r}=-0.18$ & $\begin{array}{l}\mathrm{p} \leq 0.58 \\
(N=12)\end{array}$ & $r=-0.62$ & $\begin{array}{l}\mathrm{p} \leq 0.03 \\
(N=12)\end{array}$ & $\mathrm{r}=-0.59$ & $\begin{array}{l}\mathrm{p} \leq 0.04 \\
(N=12)\end{array}$ \\
\hline & $\begin{array}{r}\text { Five year per } \\
\text { capita } \\
\text { GDP growth }\end{array}$ & $\mathrm{r}=-0.01$ & $\begin{array}{l}\mathrm{p} \leq 0.99 \\
(N=12)\end{array}$ & $r=-0.59$ & $\begin{array}{l}\mathrm{p} \leq 0.04 \\
(N=12)\end{array}$ & $r=-0.56$ & $\begin{array}{l}\mathrm{p} \leq 0.06 \\
(N=12)\end{array}$ \\
\hline & $\begin{array}{r}\text { Unemployment } \\
\text { rate }\end{array}$ & $\mathrm{r}=-0.39$ & $\begin{array}{l}\mathrm{p} \leq 0.21 \\
(N=12)\end{array}$ & $\mathrm{r}=-0.49$ & $\begin{array}{l}\mathrm{p} \leq 0.10 \\
(N=12)\end{array}$ & $\mathrm{r}=-0.39$ & $\begin{array}{l}\mathrm{p} \leq 0.21 \\
(N=12)\end{array}$ \\
\hline $\begin{array}{c}\text { Human } \\
\text { Development }\end{array}$ & $\begin{array}{r}\text { Human } \\
\text { Development } \\
\text { Index }\end{array}$ & $\mathrm{r}=-0.19$ & $\begin{array}{l}\mathrm{p} \leq 0.53 \\
(N=12)\end{array}$ & $r=-0.75$ & $\begin{array}{l}\mathrm{p} \leq 0.005 \\
(N=12)\end{array}$ & $r=-0.67$ & $\begin{array}{l}\mathrm{p} \leq 0.02 \\
(N=12)\end{array}$ \\
\hline
\end{tabular}


Table 4: Regression of Macro Indicators on Social Inequality Index (MDII) and Gini Index for Income Inequality

\begin{tabular}{|c|c|c|c|c|c|c|c|}
\hline & Political Stability & $\begin{array}{c}\text { Government } \\
\text { Effectivenes } \\
s \\
\end{array}$ & $\begin{array}{c}\text { Freedom } \\
\text { House } \\
\text { Score } \\
\end{array}$ & $\begin{array}{c}G D P \\
\text { per capita }\end{array}$ & $\begin{array}{c}\text { Five year } \\
\text { per capita } \\
\text { GDP growth }\end{array}$ & $\begin{array}{c}\text { Unemployme } \\
\text { nt Rate }\end{array}$ & $\begin{array}{c}\text { Human } \\
\text { Developmen } \\
\text { t Index } \\
\end{array}$ \\
\hline MDII & $\begin{array}{c}-12.02+ \\
(6.52)\end{array}$ & $\begin{array}{l}-16.44 \\
(9.81)\end{array}$ & $\begin{array}{c}11.32 \\
(25.46)\end{array}$ & $\begin{array}{c}- \\
90820.12 * \\
(39940.98) \\
\end{array}$ & $\begin{array}{l}-60.48 * \\
(25.12)\end{array}$ & $\begin{array}{l}-33.09 \\
(23.08)\end{array}$ & $\begin{array}{l}-1.49 * * \\
(0.46)\end{array}$ \\
\hline $\begin{array}{l}\text { Gini } \\
2007\end{array}$ & $\begin{array}{l}-0.01 \\
(0.03) \\
\end{array}$ & $\begin{array}{c}0.015 \\
(0.051) \\
\end{array}$ & $\begin{array}{c}0.08 \\
(0.13) \\
\end{array}$ & $\begin{array}{c}4.91 \\
(206.04) \\
\end{array}$ & $\begin{array}{c}0.09 \\
(0.13) \\
\end{array}$ & $\begin{array}{l}-0.11 \\
(0.12) \\
\end{array}$ & $\begin{array}{ll}-0.000 \\
(0.002)\end{array}$ \\
\hline Constant & $\begin{array}{c}1.79 \\
(1.07) \\
\end{array}$ & $\begin{array}{c}1.24 \\
(1.60) \\
\end{array}$ & $\begin{array}{l}-1.16 \\
(4.16) \\
\end{array}$ & $\begin{array}{l}14380.97+ \\
(6522.295)\end{array}$ & $\begin{array}{c}4.13 \\
(4.10) \\
\end{array}$ & $\begin{array}{l}13.47 * * \\
(3.77)\end{array}$ & $\begin{array}{l}0.97 * * \\
(\mathbf{0 . 0 7 5 )} \\
\end{array}$ \\
\hline $\mathrm{R}^{2}$ & 0.32 & 0.24 & 0.08 & 0.38 & 0.39 & 0.31 & 0.56 \\
\hline & \multicolumn{7}{|c|}{$\begin{array}{l}N=12 ; \text { Beta (standard error): }+\mathrm{p}<0.10, * \mathrm{p}<0.05, * * \mathrm{p}<0.01 \\
\text { Source: EUREQUAL Mass Publics Surveys } 2007\end{array}$} \\
\hline
\end{tabular}


Figure 1: Social Inequality Index (MDII) and Gini Index for Income Inequality

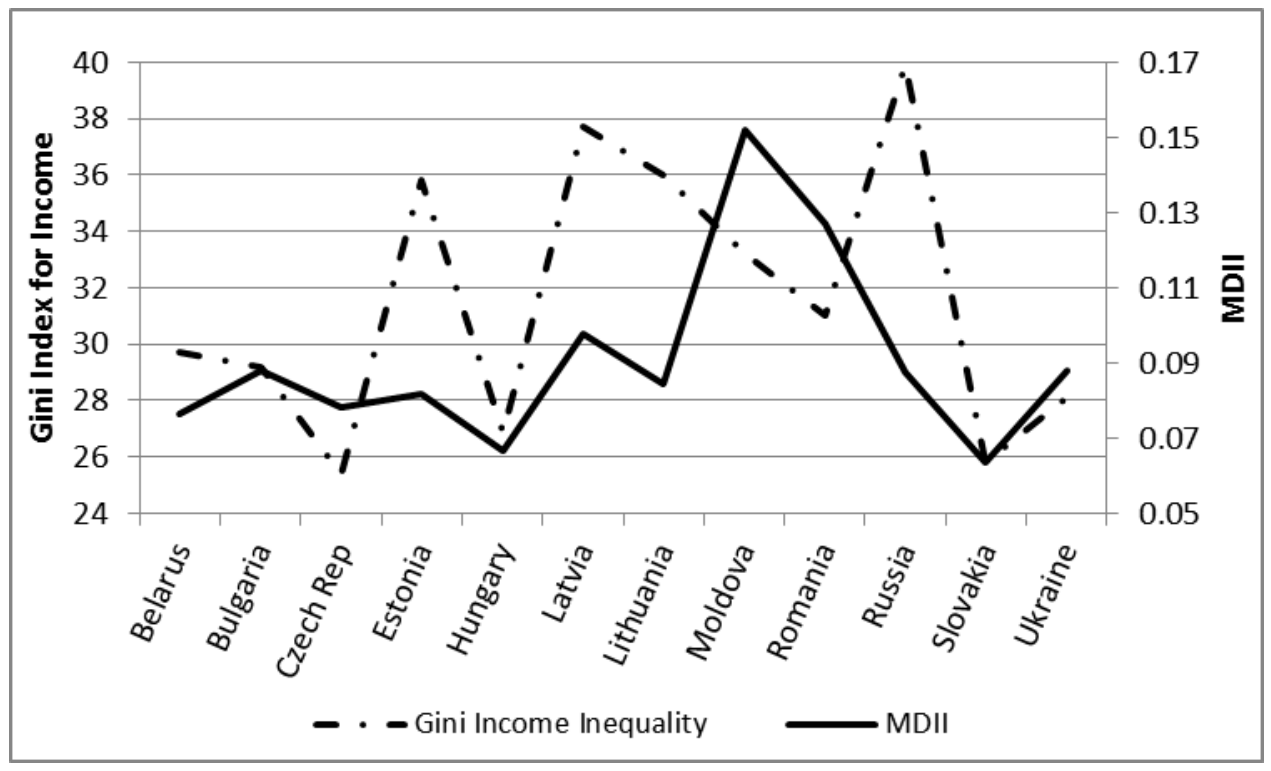




\section{APPENDIX A: THE EUREQUAL PROJECT}

The EUREQUAL project 'Social Inequality and Why It Matters for the Economic and Democratic Development of Europe and Its Citizens: Post-Communist Central and Eastern Europe in Comparative Perspective' is a cross-national project funded by the European Commission under contract No 028920 (CIT5), Framework 6.

Fieldwork was conducted in the spring of 2007. The data were collected by national surveys administered by polling institutes in each country via face-to-face interviews on the basis of stratified national random probability samples. The final dataset includes surveys conducted in $13 \mathrm{CEE}$ countries (Belarus, Bulgaria, Czech Republic, Estonia, Hungary, Latvia, Lithuania, Moldova, Poland, Romania, Russia, Slovakia, and Ukraine) with each country's data weighted to a sample size of $\mathrm{N}=1000$. The EUREQUAL original project website (http://eurequal.politics.ox.ac.uk/) provides a link both to the full codebook and to the complete original dataset.

\section{APPENDIX B: DATA SOURCES}

\section{Individual-level variables from the EUREQUAL surveys:}

Income: (L6a): "Can you tell me please what is your own monthly income before taxes from your work, pension and any other sources of income, such as child benefit, family allowances, etc. that you may have? " Open-ended response: Hungary, Moldova, and Romania. Income range categories: Belarus, Bulgaria, the Czech Republic, Estonia, Latvia, Lithuania, Poland, Russia, Slovakia, and Ukraine.

Health: M1: How would you describe your health in general? 5: Excellent; 4: Good; 3: Average; 2: Poor; 1: Very Poor.

Education: all countries were adjusted to the ISCED 1997. 0: Pre-primary; 1: Primary; 2: Lower secondary; 3: Upper secondary; 4: Post-secondary, non-tertiary; 5: First stage tertiary; 6: Second stage tertiary leading to an advanced research qualification.

Access to Health Care: L7f: Now, please compare your household's access to health care with the average access in the country as a whole? Would you say that your household's health care access is: 1: Well below average; 2: Below average; 3: Somewhat below average; 4: Average; 5: Somewhat above average; 6: Above average; 7: Well above average; Do not know (recoded to missing).

Access to Education: L7g: Now, please compare your household's access to education with the average access in the country as a whole? Would you say that your household's access to education is: 1: Well below average; 2: Below average; 3: Somewhat below average; 4: Average; 5: Somewhat above average; 6: Above average; 7: Well above average; Do not know (recoded to missing).

\section{Macro-level variables:}

GDP per capita 2007 and GDP growth 2002-2007: World Bank data: www.worldbank.org/data.html Unemployment Rate Total (\% of total labor force) (modeled ILO estimates): World Bank data:

www.worldbank.org/data.html

GINI for income inequality 2007: United Nations Development Programme:

http://hdr.undp.org/en/statistics/data/

Freedom House scores 2007: http://www.freedomhouse.org/

Governance Indicators 2007: World Bank data:

http://info.worldbank.org/governance/wgi/index.aspx\#home

Human Development Index 2007: Human Development Report 2009:

http://hdr.undp.org/en/content/human-development-report-2009 